International Journal of Engineering \& Technology, $7(3.24)(2018) 23-27$
International Journal of Engineering \& Technology
SPC
Website: www.sciencepubco.com/index.php/IJET
Research paper

\title{
Financial Impact and Causes of Chronic Musculoskeletal Disease Cases in Malaysia Based on Social Security Organization of Malaysia Claims Record
}

\author{
Norsheila Zainal Abidin ${ }^{1}$, Jafri Mohd. Rohani ${ }^{1 *}$, Athirah Nadia Nordin ${ }^{1}$, Raemy Md. Zein ${ }^{2}$, Augeny Satik anak \\ Ayak $^{1}$ \\ ${ }^{1}$ Faculty of Mechanical Engineering, Universiti Teknologi Malaysia, Skudai, Johor, Malaysia \\ ${ }^{2}$ National Institute of Occupational Safety and Health, Senai, Johor, Malaysia \\ *Corresponding author E-mail:jafrimr@utm.my
}

\begin{abstract}
This paper analyzed total direct cost that is paid by the Social Security Organization of Malaysia (SOCSO) to the Malaysian workers due to musculoskeletal disease. The objectives of this study are 1) to determine the total direct costs incurred as a result of cases of chronic musculoskeletal injuries that was approved by SOCSO from 2009 to 2014 and 2) to examine the age category imposed for the total average cost of the highest MSDs claims for the four categories setting. The data provided by SOCSO on occupational diseases and adopt the top-down approach which includes of 416 claims reported between 2009 and 2014. The categories recorded are the highest total direct cost for types of industries, types of injury, causes of accident and type of body parts. The age claimant is then identified from total average cost earned from the highest total direct cost of the four categories. Manufacturing industry, strenuous movement, sprain and strain and back are recorded as highest total direct cost with the cost of RM 5,181,282.34, RM 7,088,839.51, RM 8,753,975.13, and RM 5,526,590.69, respectively. The age group of $35-44$ years is recorded as the highest total average cost of these four parameters. This study will provide the basis for future studies and intervention on MSD related injuries in working environment in Malaysia.
\end{abstract}

Keywords: Body part location; Cause of accident; Direct cost; Injury; Musculoskeletal disorders

\section{Introduction}

Malaysia is one of the growing industrialized countries and expected to have developed country status in the next decade [1]. Industries are booming at a very high rate and therefore the hazard of occupational diseases are always considered as most significant problems for workers in the future, especially for developing countries like Malaysia [2]. Meanwhile for the developed countries such as Canada that already claims occupational diseases are common health problem and is the major contributor to the disability and cost in working for population [3]. Consequently, both developed and developing countries face the same problems and being apprehensive to all organizations nowadays.

A study conducted in the United States mentions that about 29\%$35 \%$ of occupational diseases and injuries belong to Musculoskeletal Disorder [4]. The others had reported a survey in United Kingdom Health and Safety Executive, which stated that musculoskeletal disorders were the most common disease and 37\% of working days lost were from MSD [5]. In Malaysia, a total number of 553 claims were recorded related to MSD between years 2009 until 2014 which corresponds to $25.22 \%$ of the overall occupational diseases that lead to temporary and permanent disability [6].

MSD problems are generally caused by the work-related physical risks factors such as repetitiveness, work environment, and psychosocial factors. This MSD will give labors experience of pain or discomfort in the muscles, nerves and tendons region including other soft tissue [7,8]. Database records of SOCSCO for the period 2009-2014 shows that the most occurrence body parts injury is human's back part which accounts for $50.2 \%$ followed by hip $36.5 \%$ and shoulder $2.6 \%$ [6]. However, the percentage of claimants will be vary depending on the scale of sectors. There is a study that shows MSD commonly occurred at lower back $48 \%$, shoulder $13 \%$,upper extremities $5 \%$, knee $5 \%$, ankle or foot $2 \%$ and multiple sites 5\% [9]. The other researcher specified the lumbar spine for most frequent cases of MSD [4, 9].

MSD causes loss of workdays that affect the productivity of business and after that creates negative economy on individual and community [6]. MSDs cases have damaged about the US \$171.7 million of productivity losses in Columbia in 2005 [10]. The productivity can be related to the efficiency between the input and output of the workers but the problem arise when that number of output unit becomes less than input hours due to workers being away from work due to illness and absenteeism [11, 12]. While the study in Korea shows that the economic cost of MSD was estimated to be $\$ 6.89$ billion, which represent $0.7 \%$ of the Korean gross domestic product in 2008 [13].

The study in the United States differentiates the cost between direct cost and indirect cost [3]. Direct cost is classified as an illness cost being compensated, medical cost, indemnity cost and others related cost during the claimants' recovery. Meanwhile, indirect cost basically refers to the losses of potential output, at work or home this lead to morbidity or premature mortality and reduction 
of quality life [14]. In a separate study, the researcher had proposed three cost categories in estimating the cost related to MSDs. The three categories include of direct cost, indirect cost, and quality of life cost [10]. Meanwhile, the other researcher defined the cost into three categories which are a direct cost, indirect cost, and intangible cost [13]. According to Middlesworth indirect cost is difficult to measure as the need to consider the loss of production time, training and compensate a replacement worker and related to absenteeism filing because it is hard to determine precisely how each activity has affected the claiming [15].

Currently, there is little study being done on the cost associated with total direct cost claimed in Malaysia. There are studies being done at oversea on total direct cost which includes medical cost and wage compensation cost do not include the cost of return to work and rehabilitation cost $[3,4,10]$. Whereas, the other researchers only report compensation claims cases from SOCSO database for the period 2002 to 2006 and focusing to the nongovernmental employee [1]

This paper is limited to secondary data only and primary data are not included. Only total direct costs (compensation claim, medical cost and return to work and rehabilitation cost) are consider in this study. The purposes of this research are: 1) to determine the total direct costs incurred as a result of cases of chronic musculoskeletal injuries approved by SOCSO from 2010 to 2014 and 2) to examine the age category imposed for the total average cost of the highest MSDs claims for the three category setting which are types of industry, types of injury, causes of injury and body part.

\section{Methodology}

The descriptive data of occupational diseases claims were provided to the research team by Social Security Organization of Malaysia (SOCSO). The data is limited from the period 2009 until 2014 and adopted top down approach where only MSD cases is filtered in as to align with the scope of study. The chosen MSDs cases are due to highest claims during the five years' period compared to miners' nystagmus, hearing impairment caused by noise, any other physical causes, and agent's diseases caused vibration, and occupational vitiligo. In addition, only permanent disability MSDs cases with paid status were accounted and others type of status (i.e. claim rejected, wrong data entry, incomplete documents and no payment made) were filtered out in order to validate the data.

As to achieve the objective of this study, the cost of medical and return to work and rehabilitation were then collected at each selected branches. The selected branches were chosen by comprising the highest percentage with the others branches that accumulating $77.5 \%(\mathrm{n}=416)$ from the overall reported by SOCSO (537 cases) The selected branches were Melaka $(n=207)$, Butterworth $(n=55)$, Sungai Petani $(n=49)$, Kuantan $(n=49)$, Kuala Lumpur (30) and Rawang (26). The collection data varied depending on each branch and losing of many data is possible due to lack of record keeping. The data of claimants such as name and identification number are not reporting in this study as to protect the claimants' personal data.

The critical part in collecting the cost data for this study is the financial and distribution of cost due to confidential data. Hence, the authority permission is needed in order to have data from the SOCSO branches. The main idea of visiting the main SOCSO office, located at Jalan Ampang, is to get an overview on how the cost is being distributed to the claimants. Return to work and rehabilitation cost record is only kept by the main SOCSO branches. Meanwhile, the medical cost claims are recorded by every SOCSO branches. The cost claims at each branch are collected through visits, emails and fax.

The process of descriptive data analysis is performed by analyzing the demographic characteristics such as gender, age groups, type of industries, causes of injury, the location of body part injuries and type of injuries. In order to determine the age category, the study in Ohio is referred. The researcher classified the into six categories which are 16-24 years, 25-34 years, 35-44 years, 45-54 years, 55-64 years and above 65 years [8]. The total direct costs were calculated from the actual payment made by SOCSO to an employee based on permanent disability cases for the year 2009 until 2014.

Statistical Package for the Social Science (SPSS) is a tool used in order to analyze the descriptive data. SPSS is one of the most popular statistical packages that can perform highly complex data manipulation. Those generations need as to manipulate the huge amount of numbers related to distribution cost between variables setting

\section{Results and Discussion}

\subsection{Compensation Cost Claimants on Type of Occupa- tional Disease}

Table 1 shows the comparison of compensation cost between MSD and other diseases case reported every year from 2009 until 2014. Table 1 shows the types of the occupational disease being reported by the SOCSO over the year 2009 until 2014. The musculoskeletal disorder has the highest cases claimed among the others diseases $25.5 \%$. The other diseases include of thirty-seven types of disease (miners' nystagmus $(21.0 \%)$, diseases caused by any other physical agents $(16.4 \%)$, hearing impairment caused by noise $(16.3 \%)$, occupational vitiligo ( $6.0 \%)$, diseases caused by vibration $(5.8 \%)$, diseases caused by chemical agents (1.7\%), any other respiratory diseases $(1.2 \%)$, and the rest of thirty-one other diseases counted less than $1 \%$. From the Table 1, the total cost incurred in the occupational diseases is increasing over the periods. For the year 2009, MSD cost was RM 1,049,700.86. The year 2010, the cost increased to RM 912,485.64 even though the sample size was same as of the year 2009. Meanwhile, for the year 2011 the total cost claim had slightly increased to RM $1,791,629.86$ compared to the year 2009. The claimant for the year 2012 increased and the consequent of cost significantly grew to RM 3,274,073.07. The number of claimants is dropping to $n=101$ that cost RM 2,624,981.55 for the year 2013. For the year 2014 the total cost was costlier compare for the year 2012, RM $3,940,486.61$. This lead to the total cost of 537 MSD claims to be RM 13,593,357.59. The occupational has clear increasing trend over the years. The total cost for year 2009 is RM 1,599,074.26, RM 3,722,228.27 for year 2010, RM 4,714,369.26 for year 2011, RM 6,148,457.45 for year 2012, RM 8,163,071.11 for year 2013 and the total cost drastically increased for year 2014 with the sum up claimants $n=1567$ (RM 34,465,120.24). The accumulated number of occupational diseases made up to $n=2104$ claimants with average total cost mean RM 22,841.48.

\subsection{Total Direct Cost Claimants on Socio-Demographic}

Table 2 shows the total direct average cost claims for sociodemographic characteristic for period 2009 to 2014. Male workers were recorded as higher claimants with average mean cost RM $28,220.00$ as compared to female workers with the average cost RM 20,600.00. The age between 35-44 years old significantly shows the highest average total direct cost claims with RM $28,264.42(38.9 \%)$. This category of age also has the highest total direct cost compared to the other category with costing of RM $4,578,835.89$ for that particular age. For the second higher claims on average total direct cost was at age 25-34 (RM 28,029.98) and then at age $45-54(\mathrm{RM} 23,934.81)$ follow to claimants from age 16 24 (RM 18,488.10) and the least average total direct cost was on age 55-64 ( RM 15,161.27). 
Table 1 Total cost for Occupational Disease (2009 to 2014)

\begin{tabular}{ccccc}
\hline \multicolumn{4}{c}{$\begin{array}{c}\text { Musculoskeletal } \\
\text { Compensation Cost }\end{array}$} & \multicolumn{2}{c}{$\begin{array}{c}\text { Other Diseases } \\
\text { Compensation Cost }\end{array}$} \\
\hline Year & $\mathbf{n}$ & $\mathbf{R M}$ & $\mathbf{n}$ & $\mathbf{R M}$ \\
2009 & 40 & $1,049,700.86$ & 81 & $1,599,074.26$ \\
2010 & 40 & $912,485.64$ & 181 & $3,722,228.27$ \\
2011 & 74 & $1,791,629.86$ & 222 & $4,714,369.26$ \\
2012 & 129 & $3,274,073.07$ & 276 & $6,148,457.45$ \\
2013 & 101 & $2,624,981.55$ & 355 & $8,163,071.11$ \\
2014 & 153 & $3,940,486.61$ & 452 & $10,117,919.89$ \\
Total & 537 & $13,593,357.59$ & 1567 & $34,465,120.24$ \\
\hline
\end{tabular}

Table 2. Average total direct cost claimants for socio-demographic characteristic

\begin{tabular}{|c|c|c|c|c|}
\hline Variable & $\mathbf{n}$ & $(\%)$ & $\begin{array}{l}\text { Total Direct } \\
\text { Cost }\end{array}$ & $\begin{array}{l}\text { Average total } \\
\text { direct cost }\end{array}$ \\
\hline \multicolumn{5}{|l|}{ Gender } \\
\hline Male & 322 & 77.4 & $9,086,979.96$ & $28,220.00$ \\
\hline Female & 94 & 22.6 & $1,936,435.29$ & $20,600.00$ \\
\hline \multicolumn{5}{|c|}{ Age Group } \\
\hline $16-24$ & 19 & 4.6 & $351,273.94$ & $18,488.10$ \\
\hline $25-34$ & 138 & 33.2 & $3,868,137.92$ & $28,029.98$ \\
\hline $35-44$ & 162 & 38.9 & $4,578,835.89$ & $28,264.42$ \\
\hline $45-54$ & 86 & 20.7 & $2,058,393.53$ & $23,934.81$ \\
\hline $55-64$ & 11 & 2.6 & $166,773.97$ & $15,161.27$ \\
\hline Above 65 & 0 & 0 & 0 & 0 \\
\hline
\end{tabular}

The age category number of average total direct cost follows the bell shape distribution. Even though the other researchers had set different category, but the trend is still following the bell shape [1, $3,7,9]$. The other researcher had setting the age parameter by group them into younger and older category. The authors had set the claimants' age below 45 years old as younger and above 45 years old as older and the authors also had stated that the claims are high for younger worker $[6,16]$

\subsection{Total Direct Cost Claimants on Chronic MSD Re- lated to Types Industry, Causes Injury, Types Injury and Body Part}

The claims for types industry were total up to 23 types of industry including manufacturing sectors, administration, services, civil ,farming, education and others industry. Most of the total direct cost claims were from manufacturing industry accounted RM $5,181,282.34$ and accumulated near to $50 \%$ from overall cost other than others industry. In the manufacturing industry, male workers compensate approximate total direct cost RM 4,455,094.00 and female worker were costing RM 726,188.27. The average total direct cost claims for manufacturing most frequently at age 35-44 (RM 31,453.3) which is $25.5 \%$ from the others age categories. The others types industry shows a digit percentage in its distribution of total direct cost. The least of total direct cost were from supporting services to water transport industry (RM 33,842.90).All claimants from the types of industry have been summarized in Table 3 .

Table 3. Total Direct Cost Based on Types Industry

\begin{tabular}{lccc}
\hline \multirow{2}{*}{ Types of Industry } & \multicolumn{3}{c}{ Total Direct Cost } \\
\cline { 2 - 4 } & n & Sum & \% \\
\hline Manufacturing & 18 & $5,181,282.34$ & 47.0 \\
other services & 5 & & \\
Iron and Steel Basic industries & 29 & $988,636.54$ & 9.0 \\
Personal services & 36 & $865,306.98$ & 7.8 \\
Business services, exc. machinery and & 33 & $804,805.87$ & 7.3 \\
leasing & 22 & $696,375.89$ & 6.3 \\
others industry & & & \\
General contractors incl. civil engineering & 29 & $578,633.91$ & 5.2 \\
Monetary institutions & 12 & $269,201.70$ & 2.4 \\
Electric light and power & 9 & $268,786.34$ & 2.4 \\
Social security and welfare & 6 & $232,947.74$ & 2.1 \\
Palm oil & 11 & $228,413.13$ & 2.1 \\
Printing, publishing and Allied Industries & 6 & $169,112.63$ & 1.5 \\
Research and scientific institutes & 4 & $108,351.32$ & 1.0 \\
General administration & 4 & $92,737.48$ & 0.8 \\
& 3 & $89,611.99$ & 0.8
\end{tabular}

Medical, dental and other health services

$\begin{array}{ccc}3 & 80,469.59 & 0.7 \\ 4 & 74,743.16 & 0.7 \\ & & \\ 4 & 64,943.76 & 0.6 \\ 4 & 61,986.52 & 0.6 \\ & & \\ 3 & 55,035.59 & 0.5 \\ & & \\ 3 & 42,396.30 & 0.4 \\ 3 & 35,793.57 & 0.3 \\ & & \\ 3 & 33,842.90 & 0.3 \\ \mathbf{4 1} & \mathbf{1 1 , 0 2 3 , 4 1 5 . 2} & \mathbf{1 0 0 .} \\ \mathbf{6} & \mathbf{5} & \mathbf{0}\end{array}$

Engineering, architectural and tech ser-

vices

Parts and accessories for motor vehicles

Hotels, rooming houses, camps, lodging

places

Restaurants, cafes and other eating places

Water works and supply

Other building materials and builders

$\mathrm{h} /$ wares

Supporting services to water transport

Total

$$
5
$$

The cost of MSDs is different through sectors and profession. Manufacturing is most favorite parameter used by researcher because many claimants contribute high cost on manufacturing industry. There is a study in Malaysia reported the manufacturing industry was leading on claimants between the range 2001- 2006 [1]. This is similar to the others study reported manufacturing was frequent claims [4, 9]. Manufacturing industry is a sector that produces or manufacture electrical and electronic products; chemicals, chemical products and petroleum products; wood and wood products; textiles, apparel and footwear; construction-related materials; transport equipment; and food products, beverages and others products. Manufacturing involves of mass scale and require the worker to stand and sitting for prolong hour and need to over time in time to fulfill the production target. Besides, the manufacturing sector is envisaged to expand, spurred by robust domestic demand and export-oriented industries.

Table 4 shows the type causes of injury being reported and classified by SOCSO over the periods. From the analyze, strenuous movements recorded as most frequent claims with cost RM $7,088,839.51$ with similar to $64.3 \%$ and 264 claimants highest compare to overexertion in lifting objects (59), others type of accident, over exertion in pushing or pulling objects (19), Striking against stationary objects (26) and others causes of accidents were listed in the Table 4. The strenuous movement was most occurrence at age 35-44 years with average cost RM 29,833.86. Overexertion in lifting objects and other types of the accident were recorded at age 35-44 as highest average total direct cost compares to another age category. Contrast to over-exertion in pushing or pulling object was most frequent at age 25-34 years old.

Most frequent types of injury experience on sprain and strain nearly to $80 \%$ claims of total direct cost. The cost incurred for sprain and strain was RM 8,753,975.13. Dislocation reported as the highest second place of claimable claims which incurred the total direct cost of RM 665,204.98, followed by a concussion and other internal injuries RM 653,374.58. The least cost for total direct cost was multiple injuries of different nature that cost RM 74,808.93 (7\%). The total direct cost for cause injury was distributed in Table 5. The most claimants on average total direct cost for sprain and strain were at age $35-44$ years old (RM 28,086.39).A dislocation also incurred an average total direct cost at age 35-44 years old ( RM 36,577.49). For concussions and other internal injuries, the average total of direct cost was recorded RM 50,939.32 at age 25-34.

Sprain and strain consequent to strenuous movement and the claims similarly high. Research on American Journal of Industrial Medicine 1989 reported that strain was the frequent claim and dislocation is about $31.9 \%$ of the total claimant followed by cuts, lacerations, punctures, scratches, and abrasions which was $14.9 \%$, and chemical burns was $13.4 \% .1173 \%$ on sprain and strain claims was recorded in Ohio and was the most frequent claim [9]. Similarly other research reported $35 \%$ claim was due to sprain and strain pain [5].

Sprain is a stretch or tear of a ligament, a strong band of connective tissue that connect the end of one bone with another. Meanwhile, a strain is an injury to a muscle or tendons. Tendons are fibrous cords of tissue that attach muscles to the bone. Strains often occur in foot, leg (typically the hamstring) or back. Strain is 
more likely a simple stretch in the muscle or tendon compare to sprain. The symptom of strain includes the feel of pain, muscle spasm, muscle weakness, swelling, inflammation and cramping. Typically, sprain and strain pain limit the claimants to perform their daily job efficiently. Thus, this limit is reducing the productivity of workers and consequently it will reduce the number of Malaysian Gross Domestic Product in order to fulfill domestic and international demands.

Table 4 Total Direct Cost for Causes of Injury

\begin{tabular}{llrl}
\hline Causes of Injury & \multicolumn{3}{c}{ Total Direct Cost } \\
\cline { 2 - 4 } & n & Sum & \% \\
\hline Strenuous movements & 264 & $7,088,839.51$ & 64.3 \\
& 59 & $1,542,937.56$ & 14 \\
Over-exertion in lifting objects & 20 & $529,602.02$ & 5.4 \\
Other types of accident, not classified & 19 & $590,446.88$ & 5.2 \\
Over-exertion in pushing or pulling ob- & 26 & $574,142.82$ & 4.8 \\
jects & 11 & $357,671.00$ & 3.2 \\
Striking against stationary objects & & & \\
Over-exertion in handling or throwing & & $186,988.81$ & 1.7 \\
objects & 3 & $57,458.40$ & 0.5 \\
Caught between a stationary object and a & 9 & $28,414.89$ & 0.3 \\
moving object & 2 & $26,254.41$ & 0.2 \\
Accidents not classified for lack of data & 3 & $21,613.80$ & 0.2 \\
Falls of persons on the same level & 1 & $19,045.15$ & 0.2 \\
Struck by moving objects, excl. falling & 1 & $\mathbf{1}$ & \\
object & Striking against moving objects & $\mathbf{4 1 0 2 3 , 4 1 5 . 2 5}$ & $\mathbf{1 0 0}$ \\
\hline Falls of persons from heights and into & 1 &
\end{tabular}

Table 5 Total Direct Cost for Types of Injury

\begin{tabular}{lllc}
\hline Types of injury & \multicolumn{2}{c}{ Total direct cost } & \% \\
\cline { 2 - 4 } & Count & Sum & 79.4 \\
\hline Sprains and strains & 335 & $8,753,975.13$ & 6 \\
Dislocations & 20 & $665,204.98$ & 5.9 \\
$\begin{array}{c}\text { Concussions and oth- } \\
\text { er internal injuries }\end{array}$ & 25 & $653,374.58$ & \\
$\quad \begin{array}{l}\text { Contusions and crush- } \\
\text { ing }\end{array}$ & 11 & $302,051.76$ & 2.7 \\
$\begin{array}{c}\text { Other wounds } \\
\text { Other and unspecified }\end{array}$ & 8 & $207,687.22$ & 1.9 \\
$\begin{array}{c}\text { injuries } \\
\text { Effects of weather, }\end{array}$ & 3 & $137,598.08$ & 1.2 \\
exposure" & 5 & $117,070.52$ & 1.1 \\
$\begin{array}{c}\text { Fractures } \\
\text { Multiple injuries of }\end{array}$ & 4 & $111,644.05$ & 1 \\
different nature & $\mathbf{7 4 , 8 0 8 . 9 3}$ & 0.7 \\
$\quad$ Total & $\mathbf{4 1 6}$ & $\mathbf{1 1 , 0 2 3 , 4 1 5 . 2 5}$ & $\mathbf{1 0 0}$ \\
\hline
\end{tabular}

In Table 6, back shows the highest total direct cost with RM $5,526,590.69$, with the half percent of claims. Hip incurred about $40 \%$ on total direct cost (RM 4,447,674.63) follow by abdomen (RM 269,894.88), shoulder (RM 202,493.48), knee (RM 141,679.05), trunk, multiple location (RM 99,965.29), hand (except fingers alone) (RM 72,697.32), fingers (RM 53,554.42), neck (RM 50,277.99), wrist (RM 41,612.15), and least total direct cost was at elbow (RM 7,434.10). Back and hip recorded the average total direct cost at age 35-44 respectively. Meanwhile abdomen recorded the total average cost at age 25-34.

Other researchers have specified the specific part of the body's back region as the lumbar spine or lower back and this body part records most frequent MSD claims [3, 9, 16, 17]. According to Murphy and Courtney lumbar spine pain was the main contributor reported in many industries and represent $25 \%$ of the cost claims [18]. In this data were not provided the specific of the body part on back pain. It probably includes all of the lower back pain and upper back pain. Back pain is definitely a common pain for the both industry and developed countries, with up to 50 percent of claimants suffering over the period year of 2009 until 2014. Back pain lead to disability adjusted life years and major of absenteeism [19].
Table 6 Total Direct Cost for Body Part

\begin{tabular}{llll}
\hline Body Part & \multicolumn{3}{l}{ Total Direct Cost } \\
\cline { 2 - 4 } & $\mathbf{n}$ & Sum & \% \\
\hline Back & 209 & $5,526,590.69$ & 50.1 \\
Hip & 152 & $4,447,674.63$ & 40.3 \\
Abdomen & 9 & $269,894.88$ & 2.4 \\
Shoulder & 11 & $202,493.48$ & 1.8 \\
Knee & 7 & $141,679.05$ & 1.3 \\
Trunk, multiple loca- & 6 & $99,965.29$ & 0.9 \\
tions & & & \\
Hand (except fingers & 6 & $72,697.32$ & 0.7 \\
$\begin{array}{l}\text { alone) } \\
\text { Fingers }\end{array}$ & 3 & $53,554.42$ & 0.5 \\
Neck & 2 & $50,277.99$ & 0.5 \\
Wrist & 3 & $41,612.15$ & 0.4 \\
Lower limb, unspeci- & 1 & $34,402.13$ & 0.3 \\
fied location & & & \\
Leg (lower leg) & 2 & $27,040.28$ & 0.2 \\
$\begin{array}{l}\text { Feet (except toes } \\
\text { alone) }\end{array}$ & 1 & $22,437.00$ & 0.2 \\
Ankle & & & \\
Trunk and one or & 1 & $16,516.76$ & 0.1 \\
more limbs & & $9,145.08$ & 0.1 \\
Elbow & 2 & $7,434.10$ & 0.1 \\
Total & $\mathbf{4 1 6}$ & $\mathbf{1 1 , 0 2 3 , 4 1 5 . 2 5}$ & $\mathbf{1 0 0}$ \\
\hline
\end{tabular}

\section{Conclusion}

Occupational morbidity imposes major health and economic burden on individual workers, employers, and society. The SOCSO database provided the statistical data of occupational disease based on standardizing reporting. From the analyzing of the data, the chronic MSDs was determined. MSD total direct cost was reported to be amount of RM 11 billion for the five-year period, from 2009 till 2014, for the 416 claimants. This tremendous cost will greatly affect the social economy. This cost incurred shows that there is a need to concern on MSDs disease from the bottom line to the top level.

\section{Acknowledgement}

This paper is a collaboration between UTM and National Institute Occupational Health and Safety (NIOSH). Many thanks to NIOSH, especially to Ergonomic Excellence Centre for the opportunities in the joint venture and financial support through the making of this paper. In addition, I would like to express my appreciation to SOCSO for the kind cooperation in giving the data related especially on cost needs.

\section{References}

[1] Abas, A.B., Said, A. R., Mohammed, M. A. , and Sathiakumar, N. (2008) Occupational disease among non-governmental employees in Malaysia: 2002-2006. Int J Occup Environ Health, 14(4): 263-71.

[2] Abbas, M., (2015) Trend of Occupational Injuries/Diseases in Pakistan: Index Value Analysis of Injured Employed Persons from 2001-02 to 2012-13. Saf Health Work, 6(3): 218-26.

[3] Bhattacharya, A., (2014) Costs of occupational musculoskeletal disorders (MSDs) in the United States. International Journal of Industrial Ergonomics, 44(3): 448-454.

[4] Dunning, K. K. , Davis, K. G., Cook, C., Kotowski, S. E. , Hamrick, C., Jewell, G. , and Lockey, J., (2010) Costs by industry and diagnosis among musculoskeletal claims in a state workers compensation system: 1999-2004. Am J Ind Med, 53(3): 276-84.

[5] Widanarko,B. ,Legg,S., Stevenson,M., Devereux,J., Amanda E., Mannetje,M., Cheng,S. ,Douwes,J., Lis Ellison-Loschmann, McLean,D., and Pearce,N., (2011) Prevalence of musculoskeletal symptoms in relation to gender, age, and occupational/industrial group. International Journal of Industrial Ergonomics, 41(5): 561572.

[6] Jafri, M. R., Affandi, M. Z., Raemy M. R., Ismail A. R. and Mohamed (2016), Analysis of Compensation Cost Related to Musculoskeletal Disorders (MSDs) Againts Younger and Older Malaysian 
Manufacturing Workers. In Proceedings of the 2016 International Conference on Industrial Engineering and Operations Management 2016. Kuala Lumpur, Malaysia.

[7] Nur, N.M., S.Z.M. Dawal, and M. Dahari, (2014). The Prevalence of Work Related Musculoskeletal Disorders Among Workers Performing Industrial Repetitive Tasks in the Automotive Manufacturing Companies. in Proceedings of the 2014 International Conference on Industrial Engineering and Operations Management. Bali, Indonesia.

[8] Asih, S., Neblett, R., Mayer, T.G. and Gatchel, R.J., (2017). Does the Length of Disability between Injury and Functional Restoration Program Entry Affect Treatment Outcomes for Patients with Chronic Disabling Occupational Musculoskeletal Disorders?. Journal of Occupational Rehabilitation, pp.1-11.

[9] Davis, K. , Dunning, K. , Jewell, G., and Lockey, J., (2014). Cost and disability trends of work-related musculoskeletal disorders in Ohio. Occup Med, 64(8): 608-15.

[10] Piedrahita, H., (2006). Costs of work-related musculoskeletal disorders (MSDs) in developing countries, Colombia case. Int J Occup Saf Ergon, 12(4): p. 379-86

[11] Escorpizo, R., (2008). Understanding work productivity and its application to work-related musculoskeletal disorders. International Journal of Industrial Ergonomics, 38: 291-297.

[12] Van der Zee-Neuen, A., Putrik, P., Ramiro, S., Keszei, A., de Bie, R., Chorus, A. and Boonen, A., (2017). Work outcome in persons with musculoskeletal diseases: comparison with other chronic diseases \& the role of musculoskeletal diseases in multimorbidity. BMC musculoskeletal disorders, 18(1), p.10.

[13] Oh,I.H., Yoon,S.J., Seo, H.Y., Kim E.J., and Kim,Y.E., (2011). The economic burden of musculoskeletal disease in Korea: A cross sectional study. BMC Musculoskeletal Disorders.

[14] Baldwin, M.L., (2004). Reducing the costs of work-related musculoskeletal disorders: targeting strategies to chronic disability cases. Journal Electromyogr Kinesiol, 14: 33-41.

[15] Middlesworth, M (2016). Financial Burden of Musculoskeletal Disorders (MSD). [cited 2016; Available from: http://ergoplus.com/financial-burden-of-musculoskeletal-disorders-msd/.

[16] Peele, P.B., Y. Xu, and A. Colombi, (2005). Medical care and lost work day costs in musculoskeletal disorders: Older versus younger workers, in International Congress Series. 214-218.

[17] Silverstein ,B.A., Viikari-Juntura, E., and Kalat, J., (2002) Use of a prevention index to identify industries at high risk for work-related musculoskeletal disorders of the neck, back, and upper extremity in Washington State, 1990-1998. Am J Ind Med, 41(3): 149-169.

[18] Murphy ,P.L., and Courtney, T.K., (2002). Low back pain disability: relative costs by antecedent and industry group. Am J Ind Med, 37(5): p. 558-571.

[19] Connelly, L.B., Woolf, A. , and Brooks, P. (2006), CostEffectiveness of Interventions for Musculoskeletal Conditions, in Disease Control Priorities in Developing Countries. 963-980. 